\title{
Online Education Management System
}

\author{
Shuli Huang \\ College of Information Engineering, Jiangxi University of Technology, Jiangxi Nanchang
}

Keywords: Management; MVC three-tier structure; Interact and reuse

\begin{abstract}
In order to help educational administration staff to improve work efficiency and to reduce errors, the educational administration system is an assistant system to complete their daily tasks in information management. The system adopts SQL Server as the background database and mainly uses the standard MVC three-layer structures (JSP-JavaBean-Servlet three-layer architecture) development model. In this system, Servlet plays a major role in logic control and receives user requests via JSP. Then Servlet calls and initializes JavaBean and sends to the client through JSP. In this system SqlBean serves as the main connection and communication among the databases. JavaBean mainly assists JSP and Servlet to receive the user's request. JSP mainly receives and responds to the client. These components can interact and reuse, which leads to an improved development efficiency. This system can be used in three heavy tasks, i.e. school registration, scheduling courses and student grade management.
\end{abstract}

\section{Introduction}

The educational administration system has become an essential system in colleges and universities. It should not only depend on manual management, but also develop to network. Online educational administration system is a concrete application of management information system in high educational administration and this is an extremely important component in digital campus. , This system is aiming to build digital management for high educational administration and studies and to improve work efficiency of educational administration staff, other members and teaching faculty. Moreover, it can cooperate with other systems within the digital campus to achieve non-redundant and uniform Information management. High educational administration system is a huge and complex system. It can be characterised as heavy-content and a large amount of information.

The online educational administration system involves a series of educational administration related management. This system enables administrators to online input, modify and inquiry the information of students, teachers, administrators and courses. The online educational administration system has changed the traditional way of educational administration and enables performance management networked. The online educational administration system is based on $\mathrm{B} / \mathrm{S}$ structure design and development. It is different from the traditional $\mathrm{C} / \mathrm{S}$ structure. Therefore, the clients do not need to install additional software and they just need to have a browser to use this the system.

The system uses SQLServer as the background database and the standard three-layer MVC development model. In this system, Servlet plays a major role in logic control and receives user requests via JSP. The Servlet calls and initializes JavaBean and sends to the clients through JSP. In this system, SqlBean serves as the main connection and communication among the 
databases. JavaBean mainly assists JSP and Servlet to receive the user's request. JSP mainly receives and responds to the clients. This design model realises application logic, process and display logic by different components these components can interact and reuse, which leads to an improved development efficiency. Currently, it is a popular approach.

\section{Requirements analysis}

For development of any software project, requirements analysis is required and it means to analyse the existing system and propose requirements for the new system. The main task is to understand the user's needs for the software system and to express in a standardized format. Also, requirements analysis is essential to the success of a software project. In order to successfully complete the development and design of educational administration system, the first is to analyse the existing system and to find out its drawbacks and define new requirements.

Analysis of existing systems. Most of the existing the educational administration systems are based on C/S structure. Their functions are relatively old fashion and not efficient. At present, the educational administration systems are not able to meet the needs of all schools. The specific circumstances of each school are different; therefore, they have different requirements for the system. In most cases, they are likely to buy moulded educational administration systems for their own and then make improvements or modifications to certain features according to their own characteristics.

So now there is a need for a new system to compensate for the lack of existing systems and to fully utilize resources.

Feasibility analysis. Feasibility analysis is required in the development process of a software project and it plays an important role in throughout the software project. The main task is to identify problems and make sure that the defined problems are worth solving in the shortest time and with the least cost.

Operational feasibility:

Nowadays the internet has been very popular and the people have been used in the online operation and accepted online mode of operation. Additionally, the users of this system mostly are school teachers or students, who are often on the Internet and they are very familiar with internet. Therefore, the online educational administration System is feasible from the perspective of the users.

Cluster analysis of users. After analysis, the users of the online educational management system mainly use this system in:

In each school, the professional management staff, teachers or leaders manage, query and supervise students, teaching staff, classes, courses and performance.

System administrators are responsible for maintenance of the entire system, including routine maintenance and maintenance of database and history records. The design in this paper is mainly for administrators.

\section{Database Design}

Because the online educational management information system is a management information system for schools and it involves many functional modules. Moreover, the 
relationships among the various modules are relatively complex. Their data are also interrelated and highly interdependent. There are many associations between educational administration systems. In reality, it shares the databases with other subsystems. However, in order to achieve the functions of the educational administration system, here each subsystem has a stand-alone database.

Database concepts design. For the development of any management system, the design of database is crucial. This influences the relational operations of the entire system. In the database design, conceptual design is the key to the entire database. Conceptual design can vividly and adequately reflect the real world, including contacts among many objects. Moreover, it is easy to understand and fully reflects the needs of customers. Therefore, the conceptual design is more stable. Fig. 1, 2 and 3 are flow charts of databases in the system.

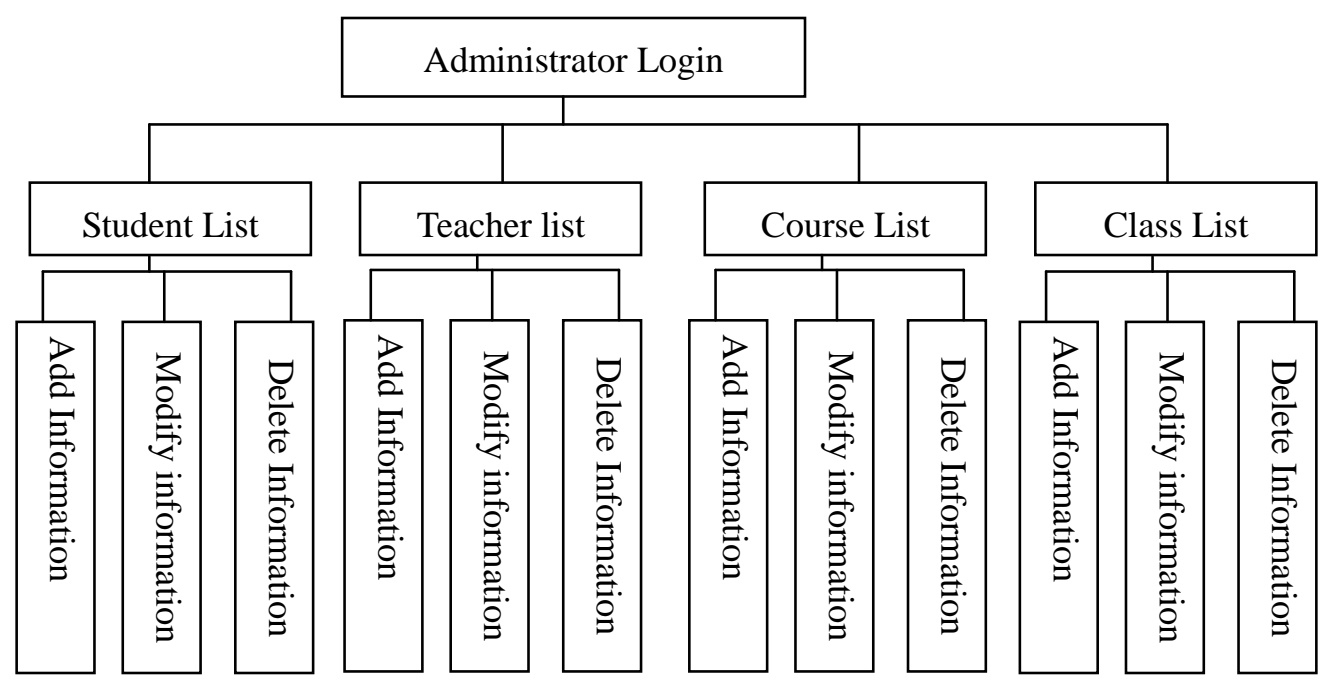

Fig. 1 Entity relationships of administrators.

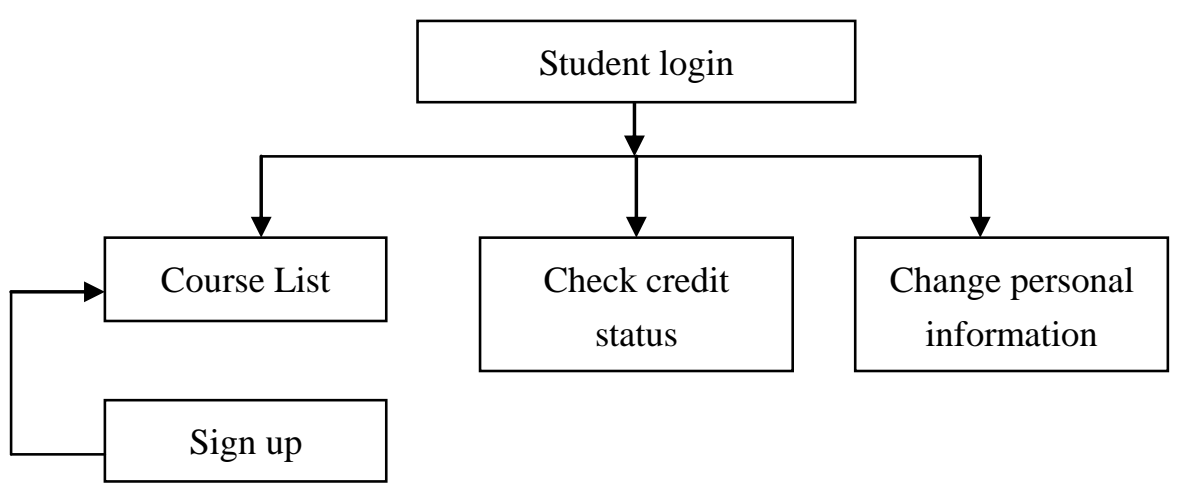

Fig. 2 Entity relationships of students. 


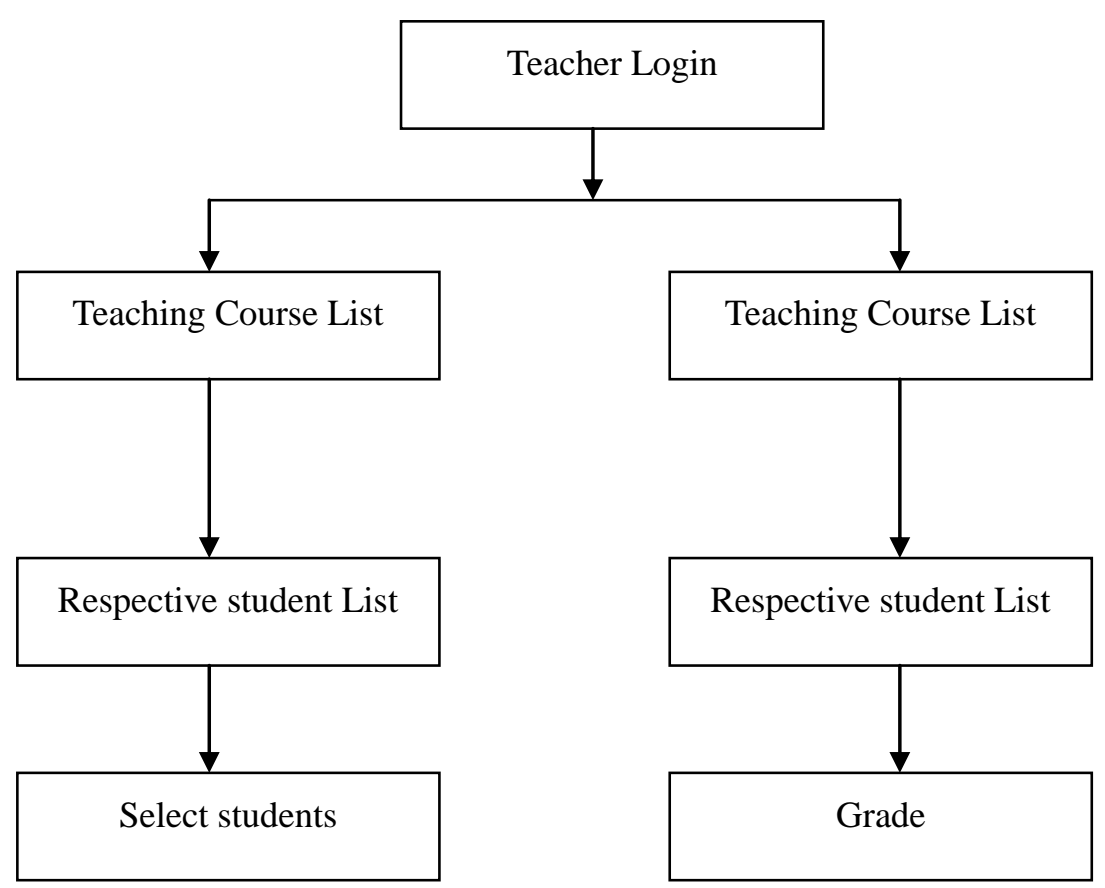

Fig. 3 Entity relationships of teachers.

In total, there are six entities. Administrator data entities: only need to record the administrator's login name, full name and password; student data entities: including student number, password, student name, sex, student major, place of birth, telephone number, e-mail. Among the information, password, telephone number and email is maintained by the student themselves. Teacher data entities include: teacher number, password, the teacher's name, title. These are initialized by the administrator, if changes have to been maintained by the administrator; course data entities: to record all the basic information about the course, mainly course number, course name, credits, department and prerequisites. The information is maintained by the school staff login as an administrator; class data entities: to record all the basic class information, including the class number, teachers, courses, classroom and class time. The data are entered and maintained by the administrator; educational administration data entities: including student number, the class, whether accepted or given credit by the teacher. The relationships between the entities are quite clear. The relationship between students and teachers is that the student selects the teacher's course, which the teacher teaches. The teacher teaches and examines the student. The relationships can be multiple, such as a student can choose many courses; a course can be selected by more than one student.

Database logic design. With the conceptual design model of the database, the logic design of the database can be achieved. The task of logic design is to transform the conceptual into the logical structure used by the datebase management system.

At present, the database has four general types, relationship, and mesh, hierarchical and object-oriented. For a particular data model, each machine system has different restrictions, so there are three steps in converting the concept model to the logical model. They are shown in the following figure: 


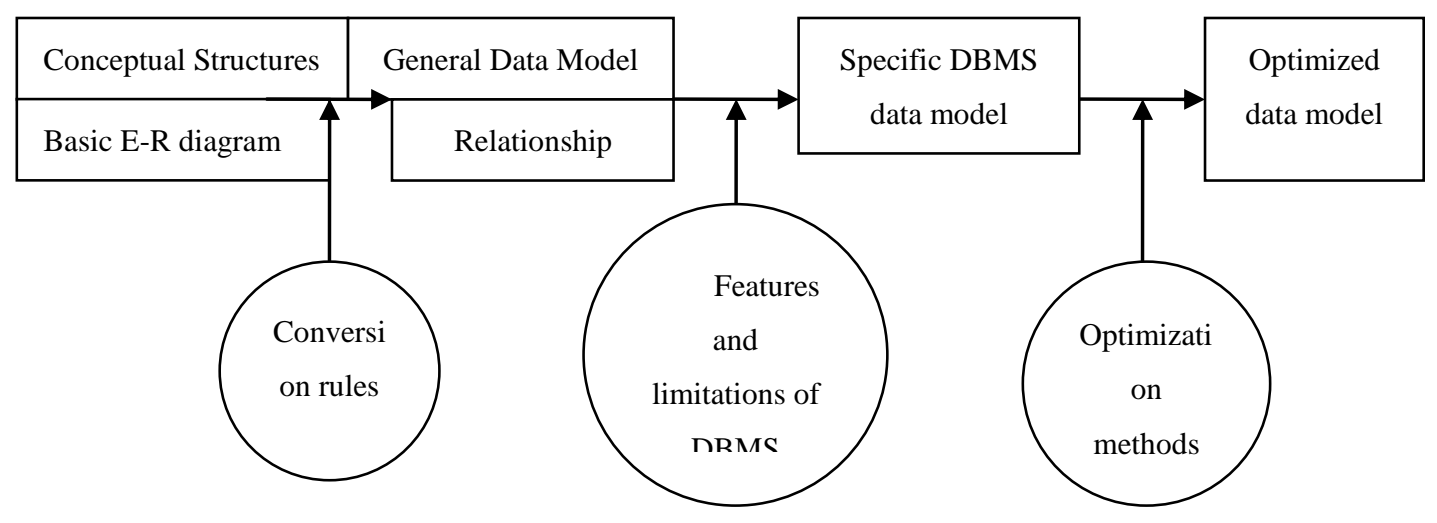

Fig. 4 Conversion of the concepts design to the logical design.

Because of the powerful functions of PowerDesiger, it can automatically generate the logical model of the database based on the concepts model of the database. However, the logic model needs to be manually modified. Fig. 5 shows a logical model of the system database.

\begin{tabular}{|c|}
\hline Admin \\
\hline$\underline{\text { ID }} \quad \frac{\operatorname{varchar} 2(20)}{\text { NAME } \quad \operatorname{varchar} 2(20)}$ \\
\end{tabular}

\begin{tabular}{|l|l|}
\hline \multicolumn{2}{|c|}{ ENROL } \\
\hline$\underline{\text { ID }} \quad \underline{\operatorname{varchar2(20)}} \quad \leq \mathrm{pk}>$ \\
CLASS_ID & $\operatorname{varchar2(20)}$ \\
ACCEPT & $\operatorname{varchar2(20)}$ \\
SCORE & $\operatorname{varchar2(20)}$ \\
\hline
\end{tabular}
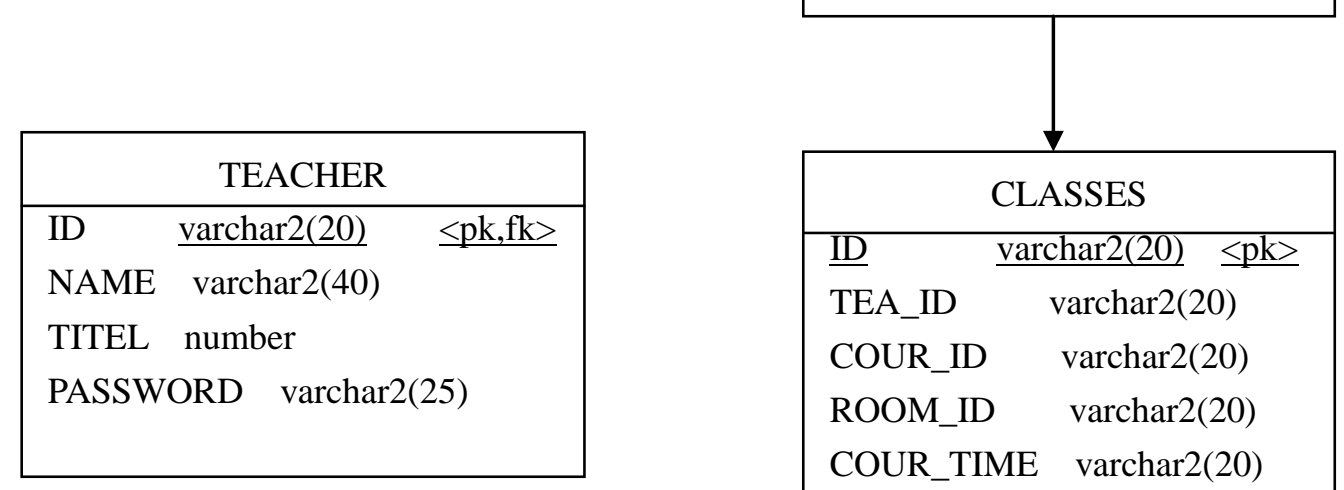

\begin{tabular}{|lc|}
\hline \multicolumn{2}{|c|}{ STUDENT } \\
\hline ID & varchar2(20) $\quad \leq \mathrm{pk}, \mathrm{fk}\rangle$ \\
NAME & $\operatorname{varchar2(20)}$ \\
PASSWORD & $\operatorname{varchar2(20)}$ \\
JIGUAN & $\operatorname{varchar2(20)}$ \\
DEPARTENT & $\operatorname{varchar2(20)}$ \\
SEX & varchar2(20) \\
MARK & number \\
TEL & varchar2(20) \\
E_MAIL & varchar2(20) \\
\hline
\end{tabular}

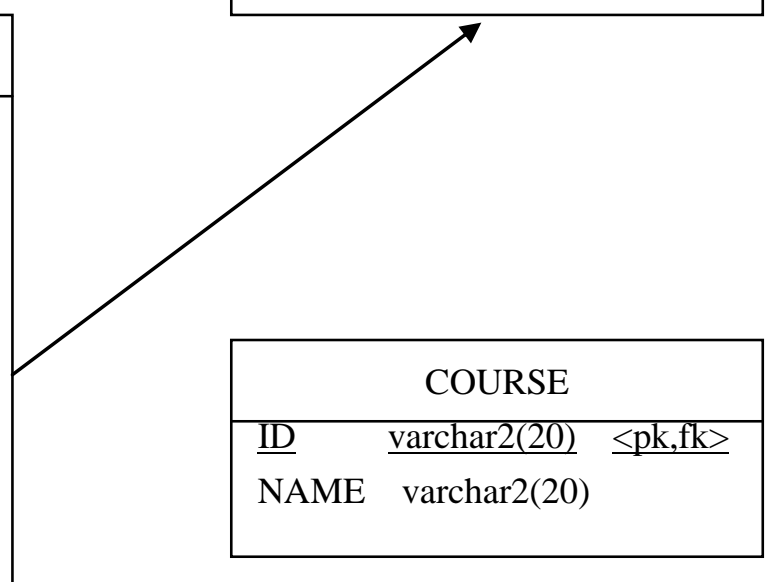

Fig. 5 Diagram of logical data model.

\section{Systems Analysis}

System functions. Functional analysis of the online educational administration system is: 
1. Add and maintain by the administrator: (1) add basic information of the administrator: add number, name and password of the administrator. (2) maintain the basic information of the administrator: modify and delete the displayed administrator information.

2. Add and maintain by the student: (1) add basic information of the student: add student number, class, and name, and sex, place of birth, telephone and e-mail. (1) maintain the basic information of the student: First select the student's class, and then modify and delete operations the displayed information of the student.

3. Add and maintain by the teacher: (1) add basic information of the teacher: Add teacher number, name and title. (1) maintain the basic information of the teacher: First select the teacher, and then modify and delete the displayed information of the teacher.

4. Add and maintain the course: (1) add basic information of the course: Add course number, name, credits and its type. (1) maintain the basic information of the course: Display course information, and then modify and delete the information.

5. Add and maintain the course selection: (1) the student selects the course: First select the course, and then select teacher, and finally confirm the selection. (1) the student searches the course: First select the course, and then confirm the results.

6. Add and maintain the teaching course: (1) add the teaching information by the teacher: select students.

7. Add and maintain the grades: (1) the main functions of the teaching teachers and the administrator module are input, modification and publication and inquiries of students' grades as well as maintenance of the grades for all student in school by the grade administrator. (2) the main function of the student module is to realize the students to check their grades online, including the courses in the current semester and they have taken previously. 
Categories of system domains. The domain categories of the online educational administration system include: class (class), teacher (teacher), students (student), curriculum (course) and so on. They and their relationships can be shown in the category map, shown in Fig. 6:

\begin{tabular}{|c|c|c|c|}
\hline 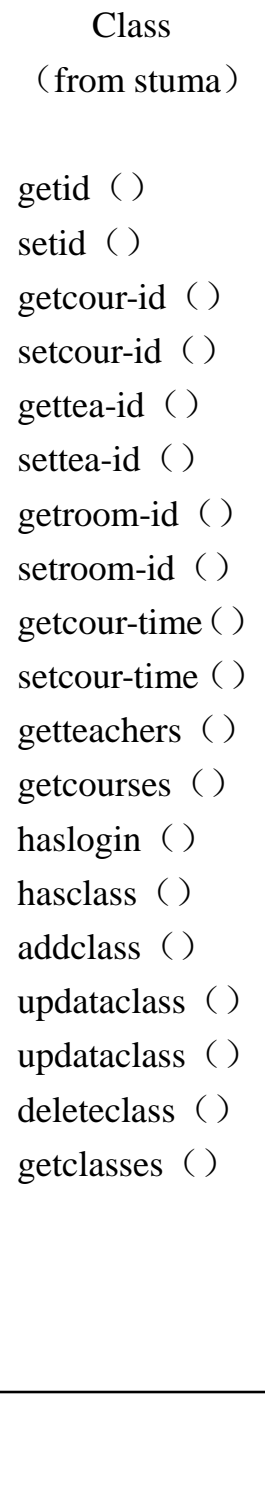 & $\begin{array}{l}\quad \text { Teacher } \\
\text { (from stuma) } \\
\text { setpassword () } \\
\text { getpassword () } \\
\text { setname () } \\
\text { getname () } \\
\text { settitle () } \\
\text { gettitle () } \\
\text { getid () } \\
\text { setid () } \\
\text { getcourse ( ) } \\
\text { haslogin ( ) } \\
\text { addteacher ( ) } \\
\text { getall () } \\
\text { update () } \\
\text { delete () }\end{array}$ & $\begin{array}{l}\text { Course } \\
\text { (from stuma) } \\
\text { setprepare ( ) } \\
\text { getprepare ( ) } \\
\text { setmark () } \\
\text { getmark ( ) } \\
\text { setdep ( ) } \\
\text { getdep ( ) } \\
\text { getname ( ) } \\
\text { setname ( ) } \\
\text { getprepares ( ) } \\
\text { setpreparedep } \\
\text { ( ) } \\
\text { getcourse ( ) } \\
\text { deletecourse ( ) } \\
\text { getpreparedep } \\
\text { ( ) } \\
\text { updatecourse } \\
\text { ( ) } \\
\text { addcourse ( ) } \\
\text { haslogin ( ) }\end{array}$ & 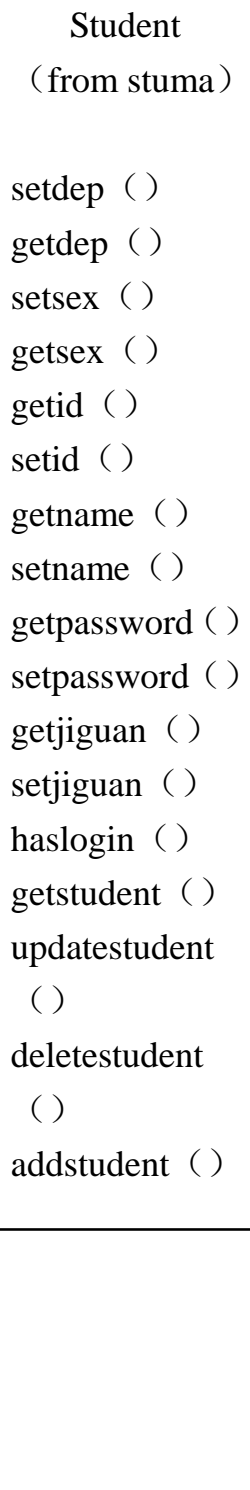 \\
\hline
\end{tabular}

Fig. 6 The category map of the educational administration domains.

\section{Overall Design}

Modules segmentation of system functions. The system is divided into six modules and each module is responsible for clear functions. Among them, the database authentication verifies the identity of the administrator and sees the user permissions. Only the administrators can use all functions. In the system, the JSP language is used to access the database. The underlying of system is a database and the system uses SQLServer based databases. 
The sub-modules together form a complete educational administration system. Its main function is to manage the staff and courses in school educational administration, including adding and maintaining the administrators, students, teachers and courses, course selection, teaching courses and grades. Because the orientation of each user system is relatively clear and the relationships among users are also clear, this system is divide according to the user groups.

Administrator management module:

Administrators $\log$ in by the login interface and add their relevant information. 1. Add and maintain by the administrator: Entry and maintenance of administrator's basic information are to modify and delete the displayed information.

Student Information Management Module:

Student module includes student information, entry and maintenance of the information: add, maintain, modify and delete student's basic information. 1. Add and maintain the course selection: the student selects course and inquiries information and confirms.

Teacher information management module:

Teacher module includes teacher's information, entry and maintenance of the information: Entry and maintenance of the teacher's basic information are to modify and delete the displayed information. Add and query the teaching course of the teacher.

Courses information management module:

Course module includes course information, entry and maintenance of the information: entry and maintenance of the course's basic information are to modify and delete the displayed information.

Course selection information management module:

The interface includes the following information: course number, name, prerequisites, department, class, time and teachers. It provides entrance of the course management, including registration.

Grade information management module:

Grade module includes grade information, entry and maintenance of the information: entry and modify and query the grade by the teacher, as well as print transcripts and maintenance of grades of all students in school. One module is serving the teacher and administrator, and the other is serving the student. (1) The main functions of the module for the teacher and the administrator are input, modification, publication and inquiries of students' grades as well as maintenance of the grades for all students in school by the grade administrator. (2) The main function of the student module is to realize the students to check their grades online, including the courses in the current semester and they have taken previously. 


\section{Structure map of system functions.}

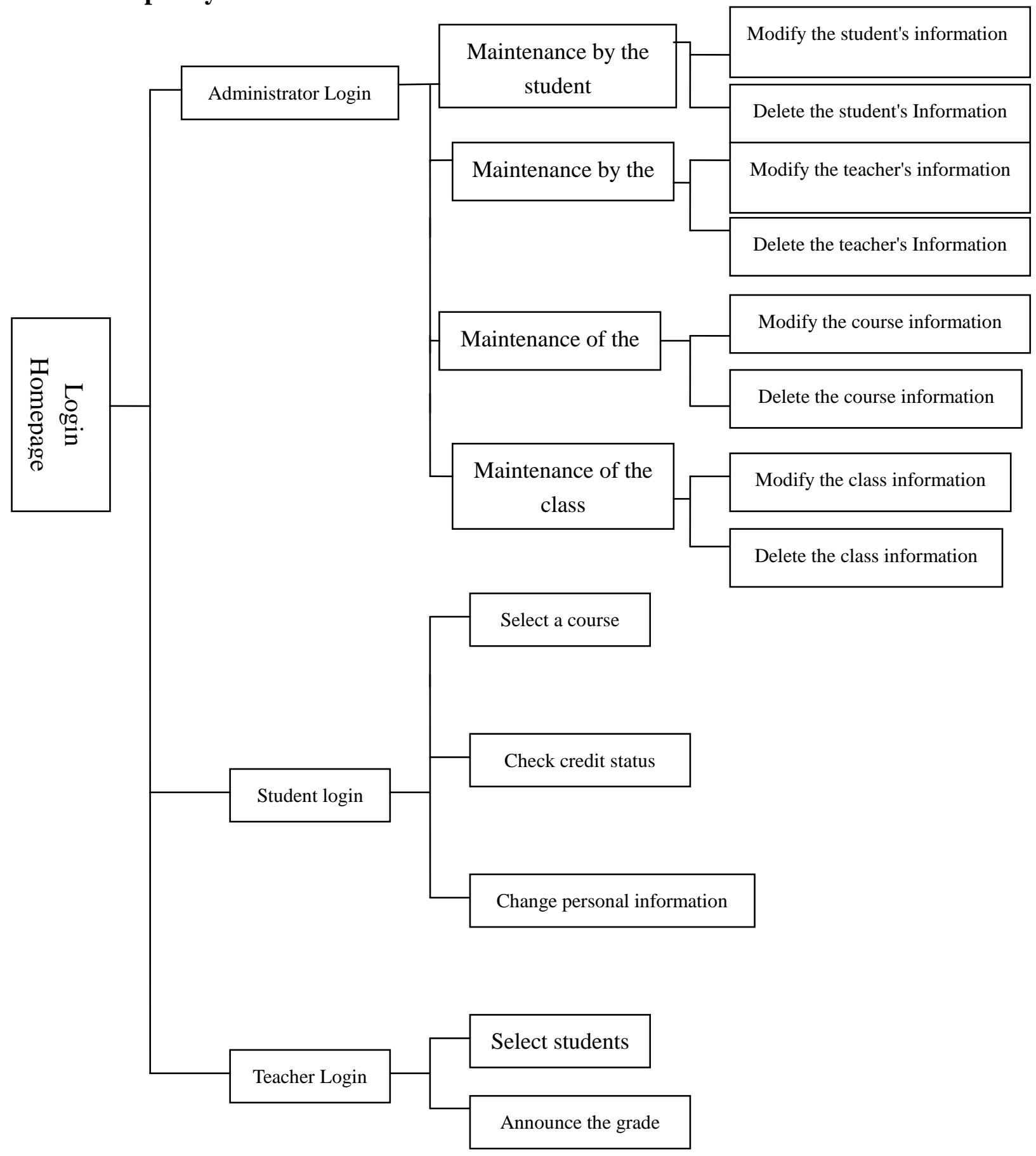

Fig. 7 Diagram of the system structure.

\section{Detailed Design}

After the cluster analysis of users, and their requirements, database design and overall design, eventually the detailed design can start. Since the B/S structure is used; the best way is to develop a prototype development methodology, and ultimately presented to the user interface is presented in the form of Web pages, so the design of the page becomes more important, plus I have adopted is based on the Struts MVC framework technology, this technology, the view (View) is the best way to communicate with the user to communicate, so 
prior to code development, you must do all of the Web page, and then encoded develop, implement functions of the system.

Webpage design. In order to keep the consistent style of the entire system, framework technology of website is used. Here is the system of the page design.

Login interface:

This is login homepage for the administrators and who have permissions above the administrators. They have to fill in the correct username and password. The system checks the database of usernames and password. If they are incorrect, this user cannot use the system. Therefore, there are two text fields, one to enter the username and another to enter its password.

Administrator interface:

If there is a need to add or maintain the administrator's information, related operations are required. The maintenance interface for the administrator is given below. Via this interface, the administrator can maintain information of the students, teachers, courses and classes. The user groups of the system clear as well as their identity.

In this interface, administrators can add, change and delete the student's information. Therefore, the information can be modified in time.

According to the definition in the requirements analysis, educational administration system manages the course. It is also one of the main objects of the teachers and students, including entry, modification and removal of the course information.

Maintenance of the course information: Find the course information you want to modify and operate. Check the displayed information in the browser and then operate. Delete and modify.

In this interface, the administrator can add, modify, delete the class information and update the information easily and timely.

Student management interface:

According to the requirements analysis, the educational administration system manages students, including entry the student's information, course selection, and their grades and so on. This interface is managed by the students themselves.

Find the student's information you want to modify and operate. Here the students can modify their own password, e-mail and telephone number.

According to the requirements analysis, the educational administration system manages the course, including entry, removal and modification of the course selection information. First, select the student's course information, and then identify all of the possible courses, and finally select a selected course.

The students can view their final grade of the selected course through this interface. This significantly reduces the workload of the educational administration staff and greatly improves their work efficiency.

Teacher management interface:

According to the definition of the requirements analysis, the teachers are managers of educational administration system. They select the students to participate in the courses and publish students' grades. This interface is maintained by the teachers.

Teachers maintain information: teachers may select the students according to the actual situation and report their grades at the end of the course for students' convenience to inquiry online. 
Teachers give students grades by this function and students can know their grades in the selected course.

Management interfaces of the educational administration:

The educational administration announcements enable students and teachers to timely grasp of all kinds of information about the school. The administrators can dynamically update news and academic information in time.

\section{Acknowledgement}

This work was financially supported by project of Technology Department of Jiangxi Province [No 20143BBM26048] and project of Jiangxi University of Technology [No. xtcx201312].

\section{References}

[1] Zhuoqun Xu, Naixiao Zhang. data structures. Beijing: Higher Education Press, 1987

[2]Li Wang. Fundamentals and Applications of Database. Beijing: China Central Radio \& TV University Press, 2002

[3] Jingyan Chen. Management Information System. Beijing: China Railway Publishing House, 1991

[4]Tao Liu, Xinghua Lou. Guidance and Examples of database development based on SQL SERVER 2000 . Beijing: People's Posts and Telecommunications Press, 2004.

[5] Shixuan Sa, Shan Wang. Introduction to Database System [M] Beijing: Higher Education Press, 2002.

[6] Fan Zhanghai. Software Engineering [M] Beijing: People's Posts and Telecommunications Press, 2002.

[7] Zhongbing Liu, Bohua Li, Chen Zou. Guidance and Examples of Database Projects based on JSP. Beijing: Tsinghua University Press, 2006. 